\title{
Pulp repair response after the use of a dentin-pulp biostimulation membrane (BBio) in primary teeth: study protocol for a randomized clinical trial
}

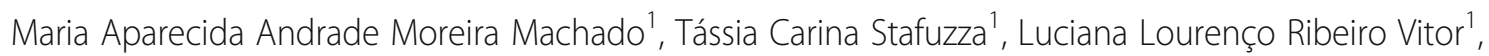
Silgia Aparecida da Costa $^{2}$, Sirlene Maria da Costa ${ }^{2}$, Natalino Lourenço Neto ${ }^{1}$ and Thais Marchini Oliveira ${ }^{1,3^{*}}$ (D)

\begin{abstract}
Background: Vital pulp therapy aims at maintaining the pulp tissue injured but vital. Thus, the use of capping materials that induce tissue regeneration is a great current trend. This study aims to evaluate clinically and radiographically the pulp repair after the use of dentin-pulp biostimulation membrane in primary teeth.
\end{abstract}

Methods: Four hundred and sixty-eight teeth from children aged between 5 and 9 years old, both genders, with deep caries lesion with pulp involvement, but no furcal impairment and any sign of necrosis will be selected. The vital pulp therapy will be performed with mineral trioxide aggregate (control group) and dentin-pulp biostimulation chitosan membrane (BBio group). The clinical and radiographic outcomes will be assessed at 12 and 24 months after treatment. The thickness of the dentin barrier will be verified through Image J2 software. The Wilcoxon signed rank test and Mann-Whitney test will respectively compare the intra- and intergroup clinical and radiographic outcomes. Paired $t$ test and independent $t$ test will respectively compare the intra- and intergroup radiographic measurements. The logistic regression will be applied, and the degrees of this association will be measured using odds ratio (OR) and 95\% confidence interval (95\% Cl).

Discussion: Therefore, this study protocol aims at new perspectives of vital pulp therapy of primary teeth by employing new easy-handling, low-cost material to keep viable the pulp tissue capable of regenerating and maintain the physiological process of deciduous tooth exfoliation.

Trial registration: Brazilian Registry of Clinical Trials RBR-6vr58b. Registered on 17 February 2019.

Keywords: Vital pulp therapy, Pulpotomy, Chitosan, Tooth, Deciduous, Pulp

\footnotetext{
* Correspondence: marchini@usp.br

${ }^{1}$ Department of Pediatric Dentistry, Orthodontics and Public Health, School

of Dentistry of Bauru, University of São Paulo, Bauru, São Paulo, Brazil

${ }^{3}$ Hospital for the Rehabilitation of Craniofacial Anomalies, University of São

Paulo, Bauru, São Paulo, Brazil

Full list of author information is available at the end of the article
}

(C) The Author(s). 2020 Open Access This article is licensed under a Creative Commons Attribution 4.0 International License, which permits use, sharing, adaptation, distribution and reproduction in any medium or format, as long as you give appropriate credit to the original author(s) and the source, provide a link to the Creative Commons licence, and indicate if changes were made. The images or other third party material in this article are included in the article's Creative Commons licence, unless indicated otherwise in a credit line to the material. If material is not included in the article's Creative Commons licence and your intended use is not permitted by statutory regulation or exceeds the permitted use, you will need to obtain permission directly from the copyright holder. To view a copy of this licence, visit http://creativecommons.org/licenses/by/4.0/. The Creative Commons Public Domain Dedication waiver (http://creativecommons.org/publicdomain/zero/1.0/) applies to the data made available in this article, unless otherwise stated in a credit line to the data. 


\section{Background}

Currently, endodontic treatments focus on reducing the pulp devitalization by either preserving or regenerating the pulp tissue after the pathologic alterations [1-4]. Regenerative procedures use materials to replace the cells or induce the remnant cells to differentiate in new pulp cells $[4,5]$.

Mineral trioxide aggregate (MTA) is the gold-standard material for clinical procedures of vital pulp therapy of primary teeth because of higher success rates in systematic reviews and meta-analysis [6-10]. Despite its biocompatibility, MTA has a longer setting time, difficult handling, high cost, and a potential for tooth discoloration [9, 11-13].

Technology and innovation aid in developing capping materials tailored for vital pulp repair and regeneration [14-19]. Thus, the search for new bioactive, biodegradable, and nontoxic material is constant $[4,20]$. In this scenario and given its commonness regenerative, antiinflammatory properties, and biocompatibility, chitosan, a natural polymer derivative of chitin, has found several applications in dentistry nowadays [21-23].

Recent studies point out that biochemical and biophysical characteristics of polymers and membranes have great potential for application in different dentistry fields [24-26]. Due the biochemical properties of chitosan and the ability to interact and stimulate pulp cells, chitosan has been exploited in association with other materials to produce new bioactive pulp dressings [23, 27]. Local antimicrobial drug delivery systems may eradicate the pathogenic microbiota or modulate the inflammatory response by decreasing the tissue destruction [4].

After the successful in vitro biophysical and biological characterization of an intraoral multilayer membrane with chitosan $[25,26]$, this study will aim to verify pulp repair response after the use of a new dentin-pulp biostimulation material in vital pulp therapy of primary teeth. The null hypothesis is that the new dentin-pulp biostimulation material will result in comparable clinical and radiographic success rate of MTA.

\section{Methods/design}

\section{Study design}

In primary teeth, vital pulp therapy goals are the pulp tissue regeneration and the maintenance of the physiological process of deciduous tooth exfoliation. Despite its biocompatibility, MTA has a longer setting time, difficult handling, high cost, and potential for tooth discoloration. Thus, this study aims to evaluate clinically and radiographically the pulp repair after the use of a new dentin-pulp biostimulation chitosan membrane in primary teeth with deep occlusal and occlusoproximal cavities reaching more than $3 / 4$ of the total thickness of carious dentin evaluated by periapical radiograph, with at least two thirds of root length. This will be a double-blinded parallel-group randomized controlled trial composed of two groups: group 1 (G1-control), teeth treated with mineral trioxide aggregate (MTA), and group 2 (G2-experimental), teeth treated with the new dentin-pulp biostimulation chitosan membrane.

Before study group assignment, the allocation concealment will be performed to trial participants in sequentially numbered, sealed envelopes. This closed envelope will include a randomization number. Allocation concealment will be ensured, as the team responsible will not release the randomization number until the patient has been recruited into the trial. The operator will open the envelope and will find the treatment condition to be conducted in the patient. The operator then gives the information about treatment allocation to the patient. The team responsible for recruitment is not allowed to receive information about the group allocation.

One primary tooth per patient will be randomly allocated in each group. If the patient has more than one tooth to include in the study, the tooth closest to the inclusion criteria will be chosen. The allocation criteria will be the cavity type (occlusal and occlusoproximal) and the child's age. Group allocation will be randomized through computerized stratified sampling (Microsoft Excel $^{\odot}$ ), independently, that is, the patients and legal guardians will remain blinded to intervention group status. Randomization will occur close to the moment of the intervention [18]. Blinding the operator during the allocation sequence and application step will not be possible. The intervention group identifier will be assigned at random and will not be identified during data analysis, that is, the examiners will remain blinded.

\section{Study setting}

Participants will be recruited at municipal schools of Bauru, Sao Paulo, Brazil. The children and legal guardians will be instructed about the research and will read and sign a free and clarified consent term. The treatments will take place in the Pediatric Dentistry Clinics of University of Sao Paulo (Bauru, Sao Paulo, Brazil). Efforts will be made to achieve adherence by explaining the treatment importance. This study will consider the patient-centered, public health, and economic outcomes. Recruitment will take place from December 2019 to August 2020. Each participant will be enrolled in the study for approximately 25 months (1 month for treatment plus 24 months of follow-up), and vital pulp therapy procedures will be performed on week 2 to week 12 . This clinical trial follows the guidelines for randomized clinical trials (SPIRIT checklist (Additional file 1)). 
Eligibility: inclusion and exclusion criteria

Inclusion criteria will comprise children aged from 5 to 9 years, from both genders, with one restorable maxillary/mandibular first/second primary molar with deep occlusal and occlusoproximal cavities reaching more than $3 / 4$ of the total thickness of carious dentin evaluated by periapical radiograph, with at least two thirds of root length. Exclusion criteria comprised no history of spontaneous pain, internal/external root resorption, fistula/abscess, and lesion at furcal area, and any sign of mobility [1,2, 28-31]. Also, by the time of clinical procedure, hemostasis will be checked and must occur within 5 min after coronal pulp exposure [28-31]. Exclusion criteria will be the presence of systemic diseases, history of allergic reaction to dental materials, and lack of hemostasis $5 \mathrm{~min}$ after coronal pulp exposure (Fig. 1).

\section{Interventions}

Clinical procedures

All clinical procedures of this study will be performed by one previously trained and calibrated operator (postgraduate student). A detailed anamnesis and clinical examination will be performed. Next, an intraoral clinical examination with the aid of dental mirror and air jet will screen eligible molars. Then, a periapical radiograph of the eligible primary molars will be taken to verify the furcal conditions. Satisfying all inclusion criteria of the study and after informed consent is given, treatment will be randomly provided in the second visit, according to previously described allocation. The patient and legal guardians will remain blinded regarding the treatment type [32].

After tooth prophylaxis with rubber cup and prophylactic paste (Herjos Tutti Frutt, Vigodent, São Paulo,

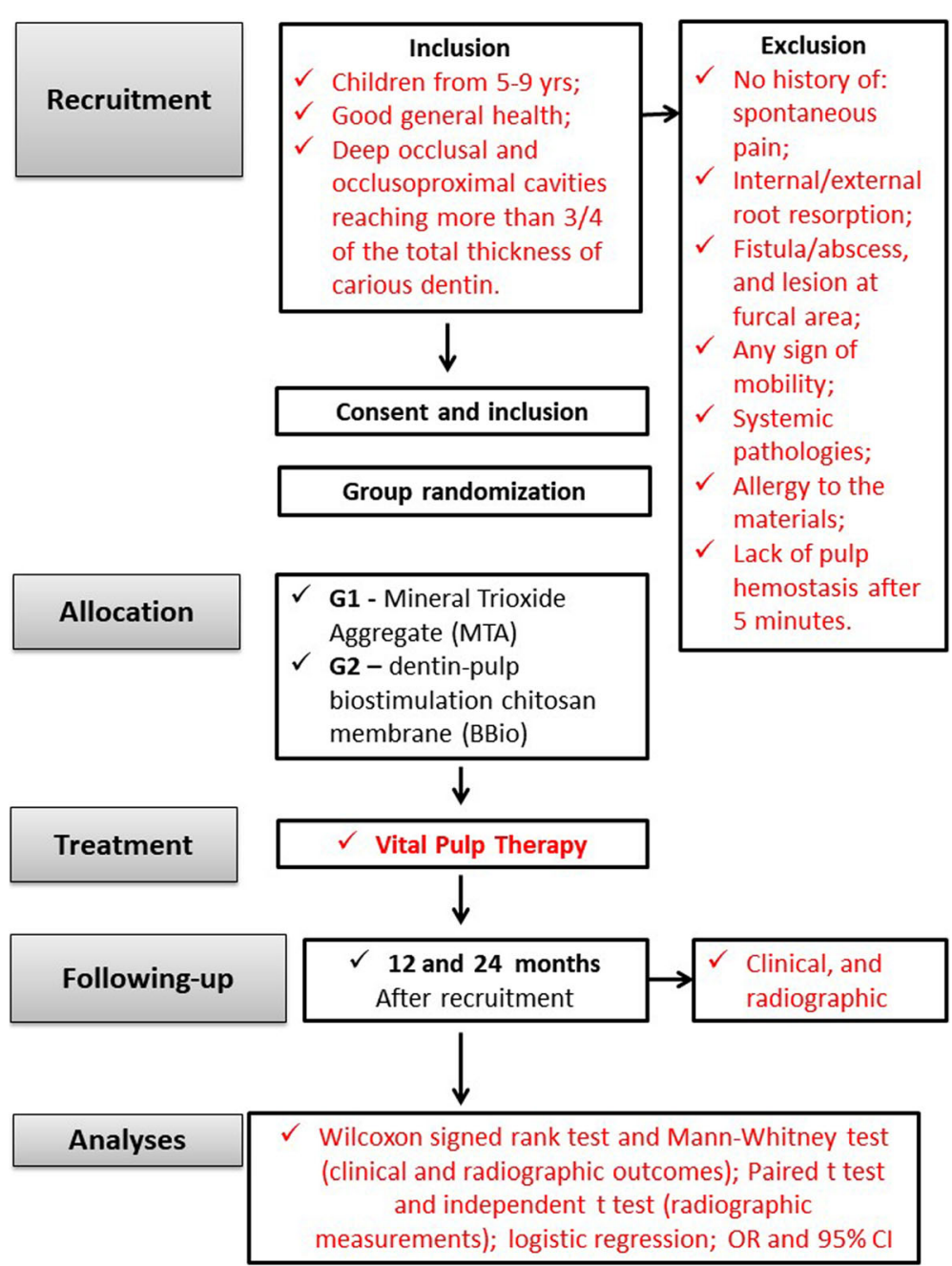

Fig. 1 Flowchart of the study 
Brazil), washing, and drying, local anesthesia will be applied (articaine 4\% + epinephrine 1:100.000) [28-31]. The cavity preparation will be performed under rubber dam isolation, using water-cooled diamond burs, and caries will be completely removed from the lateral walls and enamel-dentine junction with the aid of low speed round burs (KG Sorensen ${ }^{\oplus}$, São Paulo, Brazil). The pulp chamber roof will be removed with the aid of round diamond burs (1014-1015) at high speed under copious irrigation. The coronal pulp will be removed with the aid of hand excavators. Pulp vitality will be checked by cut resistance, red color, and hemostasis after $5 \mathrm{~min}$. If necessary, constant irrigation will be performed with sterile saline solution. Pulp stumps will be dried with sterile cotton pellets, and the capping material will be applied according the assigned group [28-31]:

- Control group-MTA (Angelus ${ }^{\oplus}$, Londrina, Paraná, Brazil) will be mixed on sterile glass plate according to the manufacturer's instruction (1 powder spoon to 1 drop of distilled water) for $30 \mathrm{~s}$ and placed onto the pulp stumps with the aid of spatula and sterile cotton pellet moistened with distilled water. A thin layer of the material will be assured, based on previous studies [14, 30, 31, 33, 34].

- BBio group - the dentin-pulp biostimulation chitosan membranes will be previously prepared in the laboratory with equal parts containing $1.5 \mathrm{~g}$ of chitosan (Sigma Aldrich, St. Louis, USA), $1.5 \mathrm{~g}$ of alginate, and $1.5 \mathrm{~g}$ portland cement-based. Each layer will be individually placed and dried at $30^{\circ} \mathrm{C}$ for 15 min. Then, the membrane (composed of three layers) will be dried for more $24 \mathrm{~h}[25,26]$. After preparation and sterilization, the membrane will be placed on the pulp stumps.

For both groups, a thin layer of liner material (Cimpat white - Septodont, Pomerode, Santa Catarina, Brazil) will be placed onto the study materials, inside the pulp chamber. The final restorations will be performed with resin-modified glass ionomer cement (Vitremer ${ }^{\ominus} 3 \mathrm{M} /$ ESPE) [28-31]. Just after vital pulp therapy, a periapical radiograph will be taken (immediate postoperative radiograph) [28-30]. The follow-up periods will be 12 and 24 months after treatment [31, 35] (Fig. 1).

\section{Radiographic procedures}

The child safety will be properly managed by the use of lead apron thyroid collar and ultraspeed x-ray films. The focus/film distance will be approximately $20 \mathrm{~cm}$, assured by universal acrylic positioning stents. A dental x-ray device with $70 \mathrm{kV}$ and $10 \mathrm{Ma}$ will be used. The exposure time will be $0.5 \mathrm{~s}$. All radiographs will be standardized using universal acrylic positioning stents (Han-Shin type). The periapical radiographs will be taken at preoperative, immediate postoperative, and 12 and 24 months of follow-up [30] (Fig. 1).

\section{Sample size}

The minimum sample size calculation was performed based on data from a previous study that found clinical and radiographic success of $94.73 \%$ for teeth treated with MTA [14]. For the sample calculation, alpha and beta errors of $5 \%$ and $20 \%$ will be respectively considered. The sample size also provides $80 \%$ power. The sample will be of 143 teeth per group to detect significant differences. A dropout rate of $20 \%$ will be estimated, and then, the number of eligible teeth will be 234 per group.

\section{Statistical methods}

All data will be analyzed using the PASW Statistics 21 software (SPSS) (IBM, Armonk, NY, USA). During all study, two trained and calibrated examiners will evaluate the treated teeth clinically and radiographically. Interand intra-examiner reliability will be verified by casual and systematic error. The Kolmogorov-Smirnov test will be adopted to test the normality of continuous variables, which will be expressed as median for the variables with a non-normal distribution and a mean value \pm SD for the variable with a normal distribution. The Wilcoxon signed rank test will compare the clinical and radiographic outcomes over period. The Mann-Whitney test will compare the clinical and radiographic outcomes between groups. Paired $t$ test will be used to compare the radiographic measurements over time. Independent $t$ test will compare the radiographic measurements between groups. The level of significance of $5 \%$ will be adopted for all comparisons. The logistic regression will be applied, and the degrees of this association will be measured using odds ratio (OR) and 95\% confidence interval $(95 \% \mathrm{CI})$.

\section{Outcomes \\ Clinical and radiographic evaluations}

The teeth will be clinically and radiographically evaluated at 12 and 24 months regarding the pulp response [28-30]. During the follow-up assessment, the following clinical criteria will be verified: spontaneous pain; any signs of mobility, sensitivity to percussion, abscess/fistula, gingival swelling not caused by poor oral hygiene, and restoration failure. The radiographic criteria will include presence/absence of internal/external resorption, signs of furcal impairment, advanced rhizolysis stage, and restoration failure including fracture and loss. Two previously trained and calibrated blinded examiners will perform the clinical and radiographic assessments. Examiners will be previously trained and calibrated in 
relation to the clinical and radiographic criteria in a pilot study, based on previous studies [30, 31, 33]. Inter- and intra-examiner reliability will be verified by casual and systematic error [36]. The examiners will fill in a form with all data for further analyses of the results.

\section{Measurement of the dentin barrier}

After the scanning of the radiographs, the images will be analyzed in Image J2 software version 64 bits (National Institutes of Health, NY, USA) [37]. The measurements on the digitized radiographs will be performed at the immediate postoperative period and 12 and 24 months of follow-up. All measurements of the scanned images will be performed by a trained and calibrated examiner blinded to the clinical procedure and the pulp capping materials to perform the measurement of dentin barrier thickness, and points will be marked on the center of the capping material layer (point A) and on the center of the furcal area (point B) [37]. Intra-examiner calibration will be determined by the casual and systematic error [36]. To assure reproducibility, each image will be measured twice at 15-day interval. The mean of these two measurements will be used for the comparisons.

\section{Data collection methods, management, and monitoring}

The clinical and radiographic aspects of teeth will be evaluated at 12 and 24 months after procedures. Data will be collected and registered on case report forms by trained researchers blinded to group allocation. Data quality will be ensured by validation checks that include missing data. Clinical and radiographic data will be inserted directly in clinical and radiographic evaluation forms. The data of the scanned $\mathrm{x}$-rays will be entered in Corel Draw version 13 software for further analysis. Data monitoring committee (DMC) will independently check data and report any problem. DMC is independent from the sponsor and competing interests. The data will be monitored by an independent clinical research assistant, one statistician, and one dental surgeon. No interim analysis beyond that described above is planned.

\section{Ancillary and post-trial care}

After completing the study, participants will continue to receive dental treatments, if needed, in the Pediatric Dentistry Clinics of University of Sao Paulo, Bauru, Sao Paulo, Brazil.

\section{Discussion}

Many pulpectomy and extractions could be avoided whether pulp regeneration therapies would be tailored for primary teeth $[4,38]$. Vital pulp therapy is routinely practiced for the treatment of primary teeth focusing on the regeneration of the dentin-pulp complex $[4,17-19,38]$. Thus, the capping material placed on the remaining pulp stumps should have the capacity of inducing the proliferation of stem and angiogenic cells of the pulp to replace the affected ones [38]. In this context, a bioactive material releases calcium ion, induces electroconductivity, produces hydrogen and calcium, and forms an interfacial layer between the material and the dentin with apatite crystals onto the material surface $[12,13]$.

According to some systematic reviews and metaanalysis, MTA has higher success rates compared to other materials [6-9]. MTA is a bioactive bioceramic endodontic cement, that is, MTA produces hydroxyapatites after hydration and induces a regenerative response by forming nanocrystals [39]. The presence of calcium trisilicate and disilicate accounts for this bioactivity [12, 40, 41]. Despite its biocompatibility, MTA has some drawbacks such as longer setting time, difficult handling, and potential for tooth discoloration [11-13].

To overcome these MTA drawbacks, different materials can be used. The current tissue bioengineering trends aim at replacing the injured cells or stimulating the growth of the injured tissue through biomaterials [4]. Accordingly, future studies should verify the effectiveness of the developing biomaterials $[4,25,26,38]$. A chitosan-based pulp dressing material seems a wise choice and provides a wise potential once this material exhibits a number of beneficial properties [23, 42]. The chitosan concentrations used to formulate the membranes are biocompatible, safe, and without side effects for humans' tissues $[25,26]$. Also, several biomedical and dental studies employing chitosan as the primary principle of membranes for tissue repair demonstrate an extensively explored field such as tablets, drug delivery systems, and more recently in tissue engineering, showing good results of biocompatibility in contact with human cells $[23,27,43,44]$.

The limitations of the present study include the disadvantages of noncompliance and high dropout rates, and the obstacle to control the period of follow-up. These disadvantages result in investigations with small sample size and the follow-up time. Further studies should be conducted, and the results should be confirmed through longer-term follow-up periods. The measurement of the dentin barrier after procedures of pulp therapy may have some limitations. This method will be used to avoid mistaken measurements due to the difficulty in evaluating the exact thickness of the dentin barrier and the overlapping of the radiographic image of the roots. One other bias of this present study will be the blinding of the operator. Although it is not possible to blind the operator during capping material application, we believe that this will not interfere in the study outcomes. Therefore, this study protocol aims at new perspectives of vital pulp therapy of primary teeth by employing new easy- 
handling, low-cost materials to keep viable the pulp tissue capable of regenerating and maintain the physiological process of deciduous tooth exfoliation.

\section{Trial status}

This trial, with protocol version 1, began in November 2019 and is still ongoing; patient recruitment is not yet complete and is planned to continue until September 2020. The first patient was included in December 2019, and the study period will end in September 2022.

\section{Supplementary information}

Supplementary information accompanies this paper at https://doi.org/10. 1186/s13063-020-04785-2.

Additional file 1. SPIRIT checklist.

\section{Acknowledgements}

Not applicable.

\section{Authors' contributions}

MAAMM conceived of the study, participated in its design and coordination, and helped to draft the manuscript. TCS will carry out the treatments, participated in the study design, and helped to draft the manuscript. LLRV will carry out the follow-up evaluation, participated in the study design, and helped to draft the manuscript. SAC will produce the membrane (BBio) for tests and participated in the study design. SMC will produce the membrane (BBio) for tests and helped to draft the manuscript. NLN will carry out the follow-up evaluation and participated in the study design. TMO will carry out the follow-up evaluation, participated in the study design, and helped to draft the manuscript. All authors read and approved the final manuscript.

\section{Funding}

This study was also financed in part by the Coordenação de Aperfeiçoamento de Pessoal de Nível Superior - Brasil (CAPES) - Finance Code 001 for publication.

\section{Availability of data and materials}

The datasets generated and/or analyzed during the current study will be available from the corresponding author on reasonable request.

\section{Ethics approval and consent to participate}

The present protocol was submitted and approved (2018) by the Ethical Committee of the University of São Paulo, Bauru, São Paulo, Brazil (CAAE: 79076017.5.0000.5417). The participants' parents or guardians will receive and sign an informed consent form prior to the child inclusion in the research.

\section{Consent for publication}

All information collected from the participants of the study will be stored in locked filing cabinets in a secure room to protect confidentiality before, during, and after the trial. Consent for publication will be obtained from the parents/legal guardians of all participants. Results of this study will be reported in full through peer-reviewed journals. Important protocol modifications will be communicated to the participants, trial register, and journals. A model of the informed consent form will be provided, if requested.

\section{Competing interests}

The authors declare that they have no competing interests.

\section{Author details}

${ }^{1}$ Department of Pediatric Dentistry, Orthodontics and Public Health, School of Dentistry of Bauru, University of São Paulo, Bauru, São Paulo, Brazil. ${ }^{2}$ Course on Textiles and Fashion, School of Arts, Sciences and Humanities, University of São Paulo, São Paulo, Brazil. ${ }^{3}$ Hospital for the Rehabilitation of Craniofacial Anomalies, University of São Paulo, Bauru, São Paulo, Brazil.
Received: 23 March 2020 Accepted: 5 October 2020

Published online: 22 October 2020

\section{References}

1. Yildirim C, Basak F, Akgun OM, Polat GG, Altun C. Clinical and radiographic evaluation of the effectiveness of formocresol, mineral trioxide aggregate, portland cement, and enamel matrix derivative in primary teeth pulpotomies: a two year follow-up. J Clin Pediatr Dent. 2016;40(1):14-20..

2. Juneja P, Kulkarni S. Clinical and radiographic comparison of biodentine, mineral trioxide aggregate and formocresol as pulpotomy agents in primary molars. Eur Arch Paediatr Dent. 2017. https://doi.org/10.1007/s40368-0170299-3 [Epub ahead of print]..

3. Lambrichts I, Driesen RB, Dillen Y, Gervois P, Ratajczak J, Vangansewinkel T, Wolfs E, Bronckaers A, Hilkens P. Dental pulp stem cells: their potential in reinnervation and angiogenesis by using scaffolds. J Endod. 2017:43(9S): S12-6.

4. Kalyan KSDR, Vinay C, Arunbhupathi UKS, Chandrasekhar R, RojaRamya KS. Preclinical evaluation and clinical trial of chlorhexidine polymer scaffold for vital pulp therapy. J Clin Pediatr Dent. 2019. https://doi.org/10.17796/10534625-43.2.7 [Epub ahead of print]..

5. Rajasekharan S, Martens LC, Vandenbulcke J, Jacquet W, Bottenberg P, Cauwels RG. Efficacy of three different pulpotomy agents in primary molars: a randomized control trial. Int Endod J. 2017;50(3):215-28..

6. Coll JA, Seale NS, Vargas K, Marghalani AA, Al Shamali S, Graham L. Primary tooth vital pulp therapy: a systematic review and meta-analysis. Pediatr Dent. 2017:39(1):16-123.

7. Dhar V, Marghalani AA, Crystal YO, Kumar A, Ritwik P, Tulunoglu O, Graham $L$. Use of vital pulp therapies in primary teeth with deep caries lesions. Pediatr Dent. 2017:39(5):146-59..

8. American Academy of Pediatric Dentistry. Pulp therapy for primary and immature permanent teeth. Pediatr Dent. 2018;40(6):343-51.

9. Stringhini Junior E, Dos Santos MGC, Oliveira LB, Mercadé M. MTA and biodentine for primary teeth pulpotomy: a systematic review and metaanalysis of clinical trials. Clin Oral Investig. 2019;23(4):1967-76..

10. Bossù M, laculli F, Di Giorgio G, Salucci A, Polimeni A, Di Carlo S. Different pulp dressing materials for the pulpotomy of primary teeth: a systematic review of the literature. J Clin Med. 2020;9(3):838.

11. Parirokh $\mathrm{M}$, Torabinejad M. Mineral trioxide aggregate: a comprehensive literature review--part III: clinical applications, drawbacks, and mechanism of action. J Endod. 2010;36(3):400-13..

12. Parirokh $\mathrm{M}$, Torabinejad $\mathrm{M}$, Dummer $\mathrm{PMH}$. Mineral trioxide aggregate and other bioactive endodontic cements: an updated overview - part I: vital pulp therapy. Int Endod J. 2018;51(2):177-205.

13. Torabinejad M, Parirokh M, Dummer PMH. Mineral trioxide aggregate and other bioactive endodontic cements: an updated overview - part II: other clinical applications and complications. Int Endod J. 2018;51(3):284-317.

14. Cuadros-Fernández C, Lorente Rodríguez Al, Sáez-Martínez S, GarcíaBinimelis J, About I, Mercadé M. Short-term treatment outcome of pulpotomies in primary molars using mineral trioxide aggregate and Biodentine: a randomized clinical trial. Clin Oral Investig. 2016;20(7):1639-45..

15. Hugar SM, Kukreja P, Hugar SS, Gokhale N, Assudani H. Comparative evaluation of clinical and radiographic success of formocresol, propolis, turmeric gel, and calcium hydroxide on pulpotomized primary molars: a preliminary study. Int J Clin Pediatr Dent. 2017;10(1):18-23..

16. Kalra M, Garg N, Rallan M, Pathivada L, Yeluri R. Comparative evaluation of fresh Aloe barbadensis plant extract and mineral trioxide aggregate as pulpotomy agents in primary molars: a 12-month follow-up study. Contemp Clin Dent. 2017:8(1):106-11..

17. Gopalakrishnan V, Anthonappa R, Ekambaram M, King NM. Qualitative assessment of published studies on pulpotomy medicaments for primary molar teeth. J Investig Clin Dent. 2019;11:e12389..

18. Çelik BN, Mutluay MS, Arıkan V, Sarı Ş. The evaluation of MTA and Biodentine as a pulpotomy materials for carious exposures in primary teeth. Clin Oral Investig. 2019;23(2):661-6.

19. El Meligy OAES, Alamoudi NM, Allazzam SM, El-Housseiny AAM Biodentine(TM) versus formocresol pulpotomy technique in primary molars: a 12-month randomized controlled clinical trial. BMC Oral Health. 2019;19(1):3.

20. Gemini-Piperni S, Takamori ER, Sartoretto SC, Paiva KB, Granjeiro JM, de Oliveira RC, Zambuzzi WF. Cellular behavior as a dynamic field for exploring bone bioengineering: a closer look at cell-biomaterial interface. Arch Biochem Biophys. 2014;561:88-98.. 
21. Muzzarelli RA, Greco F, Busilacchi A, Sollazzo V, Gigante A. Chitosan, hyaluronan and chondroitin sulfate in tissue engineering for cartilage regeneration: a review. Carbohydr Polym. 2012;89(3):723-39..

22. Croisier $F$, Jerome $C$. Chitosan-based biomaterials for tissue engineering. Eur Polym J. 2013;49:780-92.

23. Wieckiewicz M, Boening KW, Grychowska N, Paradowska-Stolarz A. Clinical application of chitosan in dental specialities. Mini Rev Med Chem. 2017; 17(5):401-9..

24. Balata GF, Abdelhady MI, Mahmoud GM, Matar MA, Abd El-Latif AN. Formulation of Saudi propolis into biodegradable chitosan chips for vital pulpotomy. Curr Drug Deliv. 2017; [Epub ahead of print].

25. Silva MD, Neto NL, da Costa SA, da Costa SM, Oliveira TM, Oliveira RC, Machado MA. Biophysical and biological characterization of intraoral multilayer membranes as potential carriers: a new drug delivery system for dentistry. Mater Sci Eng C Mater Biol Appl. 2017;71:498-503..

26. Kloster AP, Lourenço Neto N, Costa AS, Oliveira TM, Oliveira RC, Machado MAAM. Antimicrobial effect of bioadhesive oral membrane associated with chlorexidine. Br Dent J. 2018;29(4):354-8..

27. Ahsan SM, Thomas M, Reddy KK, Sooraparaju SG, Asthana A, Bhatnagar I. Chitosan as biomaterial in drug delivery and tissue engineering. Int J Biol Macromol. 2018;110:97-109.

28. Marques NC, Neto NL, de Oliveira Rodini C, Fernandes AP, Sakai VT, Machado MA, Oliveira TM. Low-level laser therapy as an alternative for pulpotomy in human primary teeth. Lasers Med Sci. 2014;30(7):1815-22..

29. Fernandes AP, Lourenço Neto N, Teixeira Marques NC, Silveira Moretti AB, Sakai VT, Cruvinel Silva T, Andrade Moreira Machado MA, Marchini Oliveira T. Clinical and radiographic outcomes of the use of Low-Level Laser Therapy in vital pulp of primary teeth. Int J Paediatr Dent. 2015;25(2):144-50.

30. Lourenço Neto N, Marques NC, Fernandes AP, Hungaro Duarte MA, Abdo RC, Machado MA, Oliveira TM. Clinical and radiographic evaluation of Portland cement added to radiopacifying agents in primary molar pulpotomies. Eur Arch Paediatr Dent. 2015;16(5):377-82..

31. Lourenço Neto N, Marques NC, Fernandes AP, Rodini CO, Sakai VT, Abdo RC, et al. Immunolocalization of dentin matrix protein-1 in human primary teeth treated with different pulp capping materials. J Biomed Mater Res B Appl Biomater. 2016;104(1):165-9.

32. Schulz KF, Altman DG, Moher D, CONSORT Group. CONSORT 2010 statement: updated guidelines for reporting parallel group randomised trials. Int J Surg. 2011;9(8):672-7..

33. Oliveira TM, Moretti AB, Sakai VT, Lourenço Neto N, Santos CF, Machado MA, Abdo RC. Clinical, radiographic and histologic analysis of the effects of pulp capping materials used in pulpotomies of human primary teeth. Eur Arch Paediatr Dent. 2013;14(2):65-71.

34. Niranjani K, Prasad MG, Vasa AA, Divya G, Thakur MS, Saujanya K. Clinical evaluation of success of primary teeth pulpotomy using mineral trioxide aggregate $\left({ }^{\circledast}\right)$, laser and biodentine(TM) - an in vivo study. J Clin Diagn Res. 2015;9(4):ZC35-7.

35. Grewal N, Salhan R, Kaur N, Patel HB. Comparative evaluation of calcium silicate-based dentin substitute (Biodentine ${ }^{\oplus}$ ) and calcium hydroxide (pulpdent) in the formation of reactive dentin bridge in regenerative pulpotomy of vital primary teeth: triple blind, randomized clinical trial. Contemp Clin Dent. 2016;7(4):457-63.

36. Houston WJ. The analysis of errors in orthodontic measurements. Am J Orthod. 1983;83(5):382-90..

37. Stafuzza TC, Vitor LLR, Lourenço Neto N, Rios D, Cruvinel T, Sakai VT, Machado MAAM, Oliveira TM. A randomized clinical trial of cavity liners after selective caries removal: one-year follow-up. J Appl Oral Sci. 2019;27: e20180700.

38. Morotomi T, Washio A, Kitamura C. Current and future options for dental pulp therapy. Jpn Dent S. 2019;55(1):5-11.

39. Jitaru S, Hodisan I, Timis L, Lucian A, Bud M. The use of bioceramics in endodontics - literature review. Clujul Med. 2016;89(4):470-3.

40. Dawood AE, Parashos P, Wong RHK, Reynolds EC, Manton DJ. Calcium silicate-based cements: composition, properties, and clinical applications. J Investig Clin Dent. 2015;0:1-15.

41. Saghiri MA, Orangi J, Asatourian A, et al. Calcium silicate-based cements and functional impacts of various constituents. Dent Mater J. 2017;36(1):8-18..

42. Shaik J, Garlapati R, Nagesh B, Sujana V, Jayaprakash T, Naidu S. Comparative evaluation of antimicrobial efficacy of triple antibiotic paste and calcium hydroxide using chitosan as carrier against Candida albicans and Enterococcus faecalis: an in vitro study. J Conserv Dent. 2014;17(4):335-9..
43. Bojar W, Kucharska M, Ciach T, Koperski Ł, Jastrzebski Z, Szałwiński M. Bone regeneration potential of the new chitosan-based alloplastic biomaterial. J Biomater Appl. 2014;28(7):1060-8..

44. Skoskiewicz-Malinowska K, Kaczmarek U, Malicka B, Walczak K, Zietek M. Application of chitosan and propolis in endodontic treatment: a review. Mini Rev Med Chem. 2017;17(5):410-34..

\section{Publisher's Note}

Springer Nature remains neutral with regard to jurisdictional claims in published maps and institutional affiliations.

\section{Ready to submit your research? Choose BMC and benefit from:}

- fast, convenient online submission

- thorough peer review by experienced researchers in your field

- rapid publication on acceptance

- support for research data, including large and complex data types

- gold Open Access which fosters wider collaboration and increased citations

- maximum visibility for your research: over $100 \mathrm{M}$ website views per year

At BMC, research is always in progress.

Learn more biomedcentral.com/submissions 